\title{
La España de Hemingway
}

\author{
GUY H. WOOD \\ Oregon State University
}

\section{INTRODUCCIÓN}

Es sabido que a Ernest Hemingway le encantaba España, que sentía una especial predilección y un cariño extraordinarios hacia este país, su gente y su cultura. Lo que voy a intentar hacer en este estudio es profundizar en esta fascinación y este amor por "lo español" que sentía Hemingway. Para llevar a cabo este análisis, habrá que acercarse a "La España de Hemingway" desde dos trayectorias diferentes. La primera trayectoria comprende la vida y la formación literaria del famoso novelista norteamericano. En esta primera parte se hará hincapié en los viajes y estancias de Hemingway en España, ya que una de las metas principales de esta aproximación a Hemingway es contestar a la siguiente pregunta: ¿Cuánto sabía verdaderamente el novelista norteamericano acerca de España? La segunda trayectoria explorará la obra de Hemingway y, más precisamente, algunos detalles de sus libros y novelas de influencia y ambientación españolas para ver cómo Hemingway aprovechó su "sabiduría española" en el momento de redactarlos. Estas obras son: Fiesta (1926), Muerte en la tarde (1932), Por quién doblan las campanas (1940), El verano sangriento (1985), y El jardín del Edén (1986). Esta últimas son obras póstumas, publicadas - sospecho - para que los herederos de Hemingway y su casa editorial pudieran aprovechar económicamente el veinticinco aniversario de la muerte del premio Nobel. Por otra parte, la publicación de estos libros y su buena venta indican que sigue habiendo un enorme interés y una gran afición a Hemingway. He aquí la razón de ser de esta indagación (1).

(1) Quisiera dar las gracias a mis amigos Alberto González Troyano, Félix Tejada, José Luis Barra y Luis 'Medrano, sin cuya ayuda y amistad este estudio hubiera sido imposible. También quisiera dar las gracias a la biblioteca John Fitzgerald Kennedy y, en particular, a Joan L. O'Connor, por su ayuda y consejos. 
Pasemos a analizar el legado español de Hemingway, empezando con lo que podría considerarse su mejor novela: la intensa y fascinante vida del propio novelista.

\section{HEMINGWAY EN ESPAÑA}

La mayoría de los estudiosos de Hemingway considera que el premio Nobel norteamericano escribió con excepcional brillantez y fecundidad entre 1925 y 1940 . Estas fechas coinciden con sus estancias más prolongadas en España y no es pura casualidad que las obras maestras de Hemingway se redacten en esa época.

Hemingway toca España por primera vez en 1919 al volver de Italia, donde había servido como voluntario en la Cruz Roja en el frente italiano durante la Primera Guerra Mundial (2). Alli fue gravemente herido al estallar un obús mientras repartía tabaco y chocolate entre los soldados italianos. En el frente y luego en Milán conoce a europeos, tiene roces con la muerte, se enamora de una enfermera y descubre una cultura diferente. Naturalmente, estas experiencias causan una impresión muy profunda en un joven de veinte años, además de ayudarle a deshacerse de su mentalidad provinciana y a conseguir confianza y sofisticación personales y sociales [M, 44].

Al llegar a su pueblo natal de Oak Park, no muy lejos de Chicago, Ernesto es recibido como un héroe. Pero, pronto le decepcionará la vida tranquila y puritana del Medio Oeste americano. Oak Park era un pueblo lleno de gente de raza blanca, donde todo el mundo era acomodado y de religión protestante [M, 54]. Allí no había ni pobres ni bares. Los padres de Hemingway eran los típicos americanos. Desde su perspectiva, Ernesto sería siempre una desgracia, una vergüenza para la familia $[M, 54]$ : nunca asistió a una universidad, bebía, escribía libros obscenos, se divorció tres veces y, aún peor, se convirtió al catolicismo [M, 54]. Años más tarde, con sus triunfos literarios, su padre exclamaría: "Ernesto ha vuelto a publicar otro libro sucio» [M, 54]. Dijo su madre de su novela Fiesta: "Es uno de los libros más sucios del año" [M, 54]. Como era de esperar, Hemingway acabó por romper con sus padres y se fue a vivir la vida bohemia de Chicago.

Ahora bien, no debe extrañarnos el que Hemingway retenga varias características de la cultura americana a lo largo de su vida. Estos rasgos

(2) Jeffrey Meyers, Hemingway: A Biography (New York: Harper and Row, 1985), p. 44. Muchos de los datos biográficos de este estudio provienen del libro de Meyers. Las referencias textuales se indican entre corchetes. 
pueden resumirse así: 1) el afán, la manía de trabajar, 2) la acuciante necesidad de "autosuficiencia», ese deseo de confianza en uno mismo y de sentirse independiente, 3) su pasión por la caza y la pesca y 4) una obsesión con la valentía personal y, en menor grado, con la violencia. $\mathrm{Mu}-$ chos de sus personajes acusan estos rasgos.

En 1921 Hemingway se casa por primera vez. Con su esposa Hadley se traslada a la ciudad canadiense de Toronto. Allí trabaja como periodista en el Toronto Star. Tampoco le agrada la vida en Canadá, y, ansioso de volver al Viejo Mundo, se las arregla para marcharse a Europa como corresponsal europeo del periódico.

Hemingway fue periodista antes de hacerse literato. Su oficio le enseña a utilizar frases cortas, párrafos breves y un inglés enérgico y preciso. Aprende a poner énfasis en la autenticidad, la comprensión y la claridad. Comprende el valor de dar la sensación de inmediatez a un escrito [M, 24]. Su aprendizaje periodístico le lleva a su teoría sobre la prosa en ficción. Compara su estilo con un iceberg. Lo que el lector ve, lee, en su obra es sólo la punta del iceberg, pero debajo de la superficie del texto está el ochenta por ciento del significado.

En el mismo año (1921), el matrimonio Hemingway se embarca para París. La capital francesa era, en aquellos tiempos, la sede de la vanguardia literaria francesa e inglesa. Hemingway tarda poco en ponerse en contacto con los otros literatos y artistas que más tarde se conocerán por el nombre de "La Generación Perdida". Durante su primer año en París, el aspirante a escritor conoce a los pintores españoles Pablo Picasso y Joan Miró, al poeta Ezra Pound, a la escritora Gertrude Stein, al novelista James Joyce, y a los novelistas americanos John Dos Passos y F. Scott Fitzgerald. Hemingway es uno de los muchos "expatriados" cuya obra se forja y cristaliza en el extraordinario ambiente parisiense de los locos años veinte.

Hemingway mezcla su vida profesional con sus diversiones predilectas. Salía de copas con James Joyce. Este era un hombre tímido y miope, pero con unas copas encima, el irlandés inevitablemente acababa discutiendo con algún forastero que apenas veía. Al llegar a las manos, diría a su inmenso amigo americano: "EEncárgate de él, Hemingway!» «¿Encárgate de éll» [M, 82]. A cambio de esta protección, Joyce enseñó a Hemingway a podar y a pulir su prosa, a sugerir el significado en vez de constatarlo [M, 83].

El boxeo era otra de sus diversiones favoritas, y Hemingway quería subir al cuadrilátero con todo el mundo. El pintor español Miró, también pequeño y delicado, y muy buen catalán, hacía de cronometrador.

Gertrude Stein, cuyos noventa kilos había que respetar, animaba a Hemingway a ir a España y le hablaba de toros y del torero Joselito. 
En 1923, acompañado de otros amigos, Hemingway hace su primer viaje a España. Quiere ver y aprender de toros. Vive en la madrileña Carrera de San Jerónimo, en una pensión frecuentada por gente taurina. Se apasiona por los toros enseguida. Para él, cada corrida es: "Una gran tragedia. Ver una corrida era [es] estar en primera fila de una guerra sin tener que sufrir las consecuencias" [M, 145]. Viaja a Sevilla, Ronda y Granada. De nuevo en París, Hemingway ya no anda por los bulevares boxeando con su sombra, sino que va dando verónicas, muletazos y estocadas, ital es su entusiasmo! cual maletilla, hasta torea con los coches y tranvías.

Aquel verano, Hemingway y su esposa vuelven a España, a Pamplona. Ninguno de los dos sabe nada de español ni nada del norte de España. Ninguno de los dos está preparado para lo que les esperaba en Navarra: encierros, bailes, una ciudad entera borracha, $y$ toros todas las tardes (3). Ven torear a Nicanor Villalta y a Manuel García "Maera». Dice Hemingway de éste: "Era muy hombre" (4). Dos de sus primeros cuentos tratan de Villalta y Maera. Hemingway se viste de pamplonica y participa de lleno en la fiesta. Escribe a casa — con su acostumbrada exageración- que todas las mañanas después del encierro él "torea" ante 20.000 espectadores, entre los que -según él— incluso hay división de opiniones. Primero están los humanitarios que quieren que desista antes de hacerse daño y, luego, los aficionados que insisten en que el americano siga toreando.

Hemingway se da cuenta enseguida que España es un yacimiento novelístico que está prácticamente sin explotar. Al igual que Colón descubre América para el Reino de Castilla, Hemingway descubre España para su feudo literario. Esta "Terra Incognita» poco a poco se convertirá en su "Tierra Prometida», en su "El Dorado», y volverá una y otra vez. Le encanta la hospitalidad española; y como muchos americanos que vienen a Europa, descubre el "arte del bien manducar". Escribe en Fiesta:

La primera comida en España siempre produce conmoción, con sus entremeses, un plato de huevos, dos platos de carne, verduras, ensaladas, fruta y postre. Hay que beber una buena cantidad de vino para poder comer todo esto (5).

(3) Carlos Baker, Emest Hemingway: A Life Story (New York: Avon, 1969), p. 146. (La traducción es mía.) Muchos de los datos biográficos de este estudio provienen del libro de Baker. Las referencias textuales se indican entre corchetes.

(4) Ernest Hemingway, Muerte en la tarde (Barcelona: Planeta, 1982), p. 77. (Las referencias textuales se indican entre paréntesis)

(5) Ernest Hemingway, Fiesta (Barcelona: Bruguera, 1985), p. 111. (Las referencias textuales se indican entre paréntesis) 
Las páginas de sus obras se llenan de jarras de cerveza y vino, de gambas, gazpacho y paellas, detalles pintorescos que ayudan a crear el ambiente y sabor españoles de su prosa. España es un país exótico: lleno de toreros, banderilleros, gitanos, etc., gente que proporcionará a Hemingway un sinnúmero de tipos y personajes. El paisaje variado, prístino, será el trasfondo de muchas de sus obras. Le intriga la personalidad española: el individualismo, el orgullo, el estoicismo, la alegría vital, la furia española y la indiferencia del español ante la muerte. Luego hay los incontables contrastes y variantes dentro del carácter español: la religiosidad y el paganismo, la sensibilidad y la brutalidad, la resignación y la rebeldía. El problema está en poder explotar y expresar todas estas experiencias vitales, emocionales e intelectuales y comprimirlas para que el lector también las viva con la misma intensidad. Para Hemingway, el escritor, al igual que un torero, "debe crear y vivir su propio estilo" [M, 118].

En 1925 los Hemingway y un grupo de amigos vuelven a Pamplona. El viaje, los amigos y las aventuras en Navarra forman la base de la primera novela de Hemingway, Fiesta. Aquel verano, Hemingway' conoce a Cayetano Ordóñez, el Niño de la Palma, torero rondeño de 19 años, quien será en Fiesta, el torero Pedro Romero. Dice Hemingway de Ordónez: "... era la misma pureza estilística con el capote... fantástico con la muleta... y mataba recibiendo" [B, 194].

En lo que queda de los años veinte, Hemingway sólo se pierde los sanfermines en 1928. Va conociendo más y más de España. Aprende español de oído y llegará a decir: "Me hubiera gustado nacer en España para poder escribir español como un nativo en vez de sentirme como un furtivo cazando en un coto o pescando durante la veda" [B, 253].

\section{LOS AÑOS TREINTA}

Durante los años treinta, la personalidad de Hemingway cambia radicalmente. Consciente de su habilidad literaria (y ya que se ha comprobado su talento con los éxitos de sus cuentos y novelas), Hemingway se esfuerza en crear una imagen pública y publicitaria de sí mismo que le va a durar el resto de su vida. De ser un humilde y sensible bruto simpático se transforma en una figura pública que arrastra una fama de mujeriego, deportista, cazador y borrachín, y todo ello encerrado en un arrogante y jactancioso "Viva yo".

Podemos observar este cambio de personalidad que se opera en Hemingway en Muerte en la tarde, su estudio sobre la tauromaquia, publicado en 1932. En un momento enjuicia a Cayetano Ordóñez así: «... empezó de una forma extraordinaria; pero, después de su primera cogida 
grave, salió con una cobardía que igualaba sólo a su habilidad para evitar el correr riesgos en la plaza" (p. 44). Al hacer unos comentarios despectivos sobre los homosexuales, pasa a describir la pintura de El Greco para constatar en español: “¡Viva El Greco, el rey de los maricones!» (p. 189). He aquí el lado crítico, cínico y oscuro de la autosuficiencia de Hemingway.

Nuestro autor sentía una necesidad apremiante de hacerse el experto, para luego poder decir la verdad y reproducir en sus cuartillas las sensaciones y emociones que experimentaba en determinada situación. Por eso, Hemingway siempre buscaba nuevos países y culturas, nuevos deportes y espectáculos, nuevos lugares donde cazar y pescar, nuevas esposas y nuevas guerras [M, 92]. La España de los años treinta le venía pintiparada. Los toros, por ejemplo, le proporcionaban una oportunidad única de estudiar y analizar lo que llegaría a ser uno de sus temas principales: la muerte. Le fascinaban los motivos que empujaban a un hombre a hacerse torero, el peligro diario que corrían los diestros y su manera de enfrentarse con la parca. A otro nivel, el de crítico taurino, Hemingway se consideraba el experto americano. Y, curiosamente, durante muchos años fue así. La corrida era su "terreno", su "territorio literario" y lo guardaba celosamente. Sólo Ernesto Hemingway podía despachar información sobre los toros. Es más, a Hemingway le gustaba identificarse con los toreros. Fue un jugador individual. Practicaba deportes solitarios, personales y violentos: el boxeo, la pesca y la caza. Hemingway convertía la faceta deportiva de su vida en un continuo desafío personal. Así podía probar y reafirmar su hombría constantemente. De esa rivalidad consigo mismo y con todo lo que le rodeaba, surgía su personalidad agresiva y egoísta. Hemingway siempre trató de llevar lo que para él era la vida de un torero. Jake Barnes, el protagonista de Fiesta dice: "Nadie vive por completo su vida excepto los toreros" (p. 18). Para Hemingway, cada enfrentamiento entre el hombre y el toro era una especie de suprema competencia en que fracasar llevaba consigo, como mínimo, un abucheo del público y la humillación personal del torero, si no una cornada o la muerte. Por eso, el torero era un ser humano sobremanera fascinante.

Hemingway se impuso una tarea sumamente difícil al acometer el proyecto de escribir un libro en inglés sobre los toros. Había que convencer al anglosajón, con su puritanismo, su miedo a la muerte y su sociedad protectora de animales, de que un espectáculo que sólo podía considerarse cruento y cruel, era digno de estudiarse. ¿Lo consiguió? Hasta cierto punto, sí. Muerte en la tarde se sigue leyendo. De hecho, se lo considera "la biblia de la tauromaquia» en inglés. Muerte en la tarde es de lec- 
tura obligatoria para todo "no aficionado» que quiera entender y profundizar en Fiesta y Por quién doblan las campanas.

Quizás el aspecto más interesante de Muerte en la tarde, para nosotros, es su valor como compendio de las impresiones que Hemingway había cosechado, a lo largo de nueve años de contacto intermitente con España. El libro está lleno de pequeñas estampas paisajísticas que muestran, claramente, el poder evocativo y nostálgico de su prosa, junto con la capacidad observadora y descriptiva del escritor. Estos esbozos' dan una muestra de su amor a España. Con ellos, rinde un homenaje personal a su país predilecto. Enseguida veremos un ejemplo.

\section{LA GUERRA CIVIL ESPAÑOLA}

A mediados de los años treinta, al estallar la guerra civil española, se opera otro cambio en la personalidad de Hemingway. Hasta este momento, Hemingway había sido objeto de críticas muy fuertes por la falta de una conciencia sociopolítica en su obra. Aunque fuese un escritor americano que escribía para un público americano, no le atraía la idea de escribir una novela acerca de las masas obreras o acerca de una huelga. Gracias a sus éxitos literarios y a sus esposas adineradas, Hemingway disfrutaba de una vida de película mientras que su país sufría las consecuencias del "crack» de Wall Street. Para el literato, su patria era un país aburrido. No obstante, en 1937 publica su única novela ambientada en los Estados Unidos. Se titula Tener o no tener. En ella, Hemingway critica tímidamente la burguesía americana y la indiferencia e ineficacia del gobierno federal. Puede que esta novela preludie el comportamiento de Hemingway durante la guerra civil.

En los años venideros, Hemingway vuelve a España cuatro veces para observar la lenta agonía de la Segunda República y sentir muy de cerca la amargura que produjo para los suyos la victoria franquista. Al volver a Estados Unidos, después de su primer viaje a España en 1937, pronuncia un discurso ante un congreso de escritores. Dice:

Sólo hay un sistema de gobierno que no puede producir buenos escritores y ese sistema es el fascismo... Un escritor que no quiera mentir no puede vivir y trabajar bajo el fascismo [B, 399-400].

Trabaja en la producción de dos películas tituladas: España en llamas y La tierra española. En ésta, Hemingway hace de interlocutor. Dice en nombre del pueblo español:

Ganamos el derecho de cultivar nuestra tierra gracias a las eleccio- 
nes democráticas. Ahora las juntas militares y los terratenientes ausentes atacan para quitarnos la tierra de nuevo. Pero luchamos por el derecho de regar y cultivar la Tierra Española. [B, 398].

Rodar y producir la película costó 13.000 dólares. Hemingway pagó la cuarta parte de su propio bolsillo. Hay unanimidad en cuanto al comportamiento de Hemingway durante la guerra civil. La tercera esposa de Hemingway dijo lo siguiente de esa época: "Creo que fue la única vez en su vida que él no era la cosa más importante que había" [M, 324]. Era valiente, generoso, un hombre que hizo todo lo posible por la República.

Ahora bien, Hemingway no volvió a España durante la guerra civil por razones puramente altruistas, ya que como corresponsal ganaba un dólar por palabra publicada. Yendo a España se escapaba de sus problemas domésticos y pudo "liarse" con otra mujer (Martha Gellhorn), la que sería su tercera esposa. También empezó a almacenar "material" para futuras obras literarias (6). Sería muy fácil criticar estas actitudes pero, recordemos que Hemingway era, ante todo, un escritor profesional.

\section{LOS AÑOS CUARENTA}

En 1940 Hemingway se traslada a Cuba, donde vivirá durante los próximos veinte años, aunque también pasa largas temporadas en el lejano oeste americano. La Habana tenía un ambiente latino, tropical, inestable y estaba llena de corrupción y vicios. Hemingway se aclimata enseguida [M, 327]. En Cuba se pone a escribir Por quién doblan las campanas, su obra más ambiciosa, en la que explotará todos sus conocimientos españoles y, en particular, sus recientes experiencias en la guerra civil.

Para Hemingway, no existía la "ficción pura». Puesto que sus obras surgían de "experiencias vividas", prefería hablar de cuentos y novelas "autobiográficos» o, cuando menos, «biográficos». Para crear un personaje literario, Hemingway utilizaba una "combinación de personajes", es decir, personajes basados en gente conocida pero con valores y rasgos añadidos por el literato. A Hemingway le gustaba «inventar verdades". Así, en Por quién doblan las campanas, el protagonista, Robert Jordan, se basa en una mezcla del mismo Hemingway y de Robert Merriman, el comandante de la Brigada Abraham Lincoln. Hay también personajes reales: Queipo de Llano, La Pasionaria, Enrique Líster, etc., y personajes inventados como: Pilar, Pablo y los otros guerrilleros [M, 3367 .

(6) Scott Dondaldson, By Force of Will (New York: Viking, 1977), p. 222. 
Hemingway gozaba escribiendo. Se consideraba un perfeccionista $y$, en esa época era extremadamente exigente consigo mismo. Madrugador, solía pasar la mañana en su estudio trabajando intensamente. A veces tardaba una mañana entera en escribir un párrafo perfecto. Llegó a escribir 32 finales diferentes para su novela Adiós a las armas [M, 219]. Este tipo de esfuerzo le dejaba extenuado y para olvidarse de su trabajo y problemas, por la tarde se dedicaba a la pesca, la caza y a otras actividades físicas que mezclaba con el alcohol. Hemingway, como otros muchos literatos americanos -Poe, Jack London, Fitzgerald y Steinbeck- era alcohólico e ingería cantidades industriales de whisky, ginebra y vino, por no mencionar la absenta [M, 351]. Su enfermedad le traería graves consecuencias y en La Habana empezó el declive. Allí escribía de pie con el lápiz en una mano y un cubata en la otra $[M, 426]$.

\section{LOS AÑOS CINCUENTA Y SESENTA}

Hemingway no 'vuelve a España hasta 1953 cuando concibe la idea de escribir un apéndice a Muerte en la tarde, y en que piensa describir los cambios y la sempiterna decadencia de la corrida de toros. Pero, después de ver torear a Antonio Ordóñez y Luis Miguel Dominguín, decide que no existe tal decadencia y que hay mucho que contar. Conoce a Ordóñez en Pamplona e inmediatamente autor y torero congenian. Pero Pamplona había perdido su encanto para Hemingway. Irónicamente, él la había convertido en otra atracción turística.

En 1956 Hemingway vuelve otra vez. Goza ya de una enorme popularidad. En los hoteles le tratan a cuerpo de rey y por la calle la gente le pide autógrafos.

Con un contrato de la revista Life, Hemingway regresa a España en 1959 para cubrir la rivalidad entre Ordóñez y Dominguín. Va a una corrida tras otra, siguiendo y persiguiendo el Mercedes de la cuadrilla Ordóñez por toda España, en una paliza automovilística que hubiera dejado para el arrastre a otro hombre de sesenta años. Vuelve a Pamplona y hace meriendas a orillas del río Irati. Hemingway dice: «En mi vida he estado más contento" [B, 588].

Al final del verano de 1959, Hemingway se pone a escribir «El verano sangriento». Señal de su deterioro físico y psicológico no es su capacidad de trabajo - el manuscrito llega a tener 120.000 palabras-, sino su imposibilidad de pulir y corregir el texto. En los años cincuenta y sesenta, la prosa precisa, escueta y poética de Hemingway se convierte en palabrería y verborrea. El verano sangriento, en su versión publicada en el año 1985, es un buen ejemplo de esta pérdida y"declive de sus 
facultades literarias. Los editores redujeron el volumen original a poco más de la mitad.

Hemingway insistirá en volver a España en agosto de 1960, pretextando que su amigo Ordóñez le necesita. Pero preso de la soledad y el insomnio, y sufriendo pesadillas, complejos de persecución y los efectos negativos de sus muchos accidentes, heridas y del alcohol, sólo se queda dos meses. Aun así demora todo lo posible su partida. Tal vez sabía entonces que no volvería nunca. Acaso el mejor epitafio y la mejor descripción de los sentimientos de Hemingway en cuanto a España, se encuentran en Muerte en la tarde. Dice:

Y aunque Madrid no tuviera más que su Museo del Prado, valdría la pena de ir a pasar allí un mes todas las primaveras... Pero cuando se puede tener al mismo tiempo el Prado y los toros, con El Escorial a dos horas apenas al Norte y Toledo al Sur, con una buena carretera que os llevará a Avila y una buena carretera que os llevará a Segovia, y a un paso de Segovia, La Granja, se experimenta realmente una pena muy grande pensando que, al margen del problema de la inmortalidad, será preciso morirse algún día y no volverlo a ver. (p. 51).

\section{LO ESPAÑOL EN LA OBRA DE HEMINGWAY}

\section{FIESTA}

Habiendo visto la formación y el legado españoles en Hemingway, lo que se pretende hacer ahora es analizar y comentar unos pasajes de la obra hemingweiana para acercarnos a "lo español» en su obra y, al mismo tiempo, llegar a una mejor comprensión de su evolución literaria.

Vamos a acercarnos primero a Fiesta, la primera novela de Hemingway, publicada en 1926. Trata de unos expatriados americanos e ingleses que viven o trabajan en París y deciden pasar sus vacaciones en Navarra y disfrutar de la fiesta de San Fermín en Pamplona. El grupo consta de cuatro hombres y una mujer', una dama inglesa, Lady Brett Ashley, que, según el narrador, está "hecha a base de curvas" y también es una "ninfómana alcohólica». Con este ambiente, obligatoriamente van a surgir conflictos y rivalidades.

Como se vio al principio, uno de los rasgos estilísticos más característicos de Hemingway es el uso del contrapunto. En Fiesta no sólo hay contrastes entre personajes, sino entre paisajes también. Nada más llegar a Pamplona, el protagonista, Jake Barnes y su amigo Bill, se marchan a Burguete para pasar unos días pescando truchas en el río Irati. 
Al principio de la novela, Jake, el narrador, describe el ambiente podrido y decadente de París con un tono obviamente despectivo. Unos ejemplos:

En París hay también otras calles tan feas y desalentadoras como el bulevar Raspail (p. 53).

Al cruzar un puente en París, dice Jake del Sena: "A nuestros pies el agua era suave y negra" (p. 92). En el tren que les lleva hacia España, el paisaje va mejorando. Escribe:

En el País Vasco, el campo da la impresión de ser rico y fructífero, y las casas y las aldeas están limpias, y parecen prósperas (p. 108).

En Burguete, los dos amigos marchan campo a través para llegar al río y gozar del sitio. El río es totalmente diferente:

... metí las botellas en el agua después de haber apretado firmemente los corchos. El agua estaba tan fría que la mano y la muñeca se me quedaron insensibles (p. 39).

Finalmente dice Jake:

Nos quedamos cinco días en Burguete, y la pesca se nos dio bien. Las noches eran frías y los días muy calurosos, pero siempre corría una agradable brisa, incluso en las horas de más calor (p. 145).

Los dos amigos se escapan del calor -del infierno- de París y Pamplona y disfrutan del ejercicio físico y del compañerismo en un sitio idílico, incontaminado y lejos de los vicios. Este contraste ciudad/campo da pie a uno de los temas principales de Fiesta: la moralidad. Y el paisaje español refleja los valores buenos y permanentes de la "tierra", sólo contaminada por la presencia humana.

Veamos un ejemplo de la "sabiduría taurina» de Hemingway, y cómo se vale de ella para crear y caracterizar a sus personajes. Lady Brett se enamora del joven e ingenuo torero Pedro Romero y lo seduce. En un ataque de celos, Robert Cohn, otra víctima de la dama, irrumpe en la habitación de Romero pillando a los dos amantes «in fraganti». Hemingway describe la pelea entre el torero y el americano, ex campeón universitario de pesos medios así: 
El torero era bastante bueno..., se lanzaba de nuevo contra Cohn cada vez que éste volvía a tumbarlo (p. 234).

Cohn lo había tumbado quince veces, pero el torero quería seguir peleando (p. 234).

Pero, aunque Romero había recibido una paliza, según el narrador, el torero "ha dejado a Cohn hecho una piltrafa humana" (p. 235).

Si recapitulamos un poco en esta imagen - la voluntad, el arrojo, la valentía de Romero- y las relacionamos con el ambiente taurino de la novela y la sabiduría taurina del autor, es obvio que se basa en la imagen de un toro bravo, noble, que embiste una y otra vez hasta encontrar la muerte. La intensidad y la emoción del combate surgen del enfrentamiento entre uno que lleva claras ventajas y otro que lleva las de perder, pero que va a vender su honor y su vida muy caros. La idea que el individuo está rodeado de fuerzas que puedan destruirlo, pero que no pueden vencerlo, al menos espiritualmente, penetra en toda la obra hemingweiana. Muchos de sus héroes caen combatiendo.

No debe extrañarnos que hasta los americanos en Fiesta se españolicen. Un amigo de Hemingway dijo lo siguiente del novelista y sus tiempos de bohemio en París: "Hemingway nunca invitó a nadie a tomar nada sino que nos convidó a todos en Fiesta... pagó las consumiciones de sus amigos en este libro" [D, 21]. Si leemos atentamente París era una fiesta, el libro que Hemingway escribió sobre sus experiencias en la capital francesa, efectivamente, se ve que el aspirante a escritor era bastante gorrón. Pero, Jake Barnes es generoso hasta el punto de ser derrochador: da buenas propinas, presta dinero a todo el mundo, y siempre está pagando una ronda o los cafés, lo que no es precisamente una costumbre norteamericana. Yo diría que Jake ha aprendido sus buenos modales en España. Veamos dos ejemplos:

La taberna estaba casi a oscuras y llena de hombres que cantaban con voces roncas y varoniles. El vino se servía directamente de grandes barricas. Puse sobre el mostrador dinero para pagar las cosas, pero uno de los mozos lo tomó y volvió a metérmelo en el bolsillo (p. 181).

Alguien que estaba junto al mostrador y que yo no había visto nunca, insistió en pagar el vino, pero finalmente logré imponerme y pagué yo. (p. 183). (Los subrayados son míos.)

Jake, que «sabe» español, que ha estado en Pamplona en muchas 
ocasiones, y está suscrito a varias revistas taurinas, tiene muchos ribetes españoles. Su "esplendidez", casi maniática - y tan típica en este países uno de sus rasgos españoles más notables. Como siempre, Hemingway combina experiencias personales con características observadas en otras personas y culturas para crear sus personajes.

\section{POR QUIÉN DOBLAN LAS CAMPANAS}

Por quién doblan las campanas, publicada en 1940 , es, como ya hemos mencionado, la novela más ambiciosa y "española» de toda la ficción hemingweiana. Trata de un americano, Robert Jordan, joven profesor de filología española de la Universidad de Montana, quien ha abandonado su puesto para volver a España y luchar en la guerra civil al lado del gobierno legítimo. La novela se ambienta en la sierra de Guadarrama, donde Robert Jordan ha ido con órdenes de volar un puente el día del comienzo de una inminente ofensiva republicana y cortar,' así, una vía de suministros y refuerzos de las fuerzas nacionales. En tres días de acción y vida intensivas, el dinamitero americano se enamora de una chica española, lucha con patrullas enemigas y participa en la vida "familiar" de la banda guerrillera de Pilar y Pablo, dos gitanos. Gracias al uso de monólogos interiores y escenas retrospectivas, el lector llega a conocer las vidas de los humildes guerrilleros junto con los antecedentes, causas y problemas de la guerra civil española. Leyendo atentamente, el lector también se acerca a la ideología de Hemingway en cuanto a la guerra. Hacía años que Hemingway detestaba a los fascistas europeos y desconfiaba de todos los políticos. De la guerra civil dijo que estaba desilusionado con "el carnaval de traición y podredumbre de ambos bandos". (7). Optó, pues, por ponerse del lado de la España democrática, $y$, en particular, de la gente humilde que tanto iba a ganar o perder en la contienda. De ahí el tono épico y trágico de la novela. Por quién doblan las campanas es una novela más prolija, detallada y lenta que las anteriores. En ella, Hemingway se ve obligado a presentar claramente los sentimientos e ideas de sus muchos personajes.

Por quién doblan las campanas ha sido objeto de muchísimos estudios, análisis y verdaderos ataques. Para Hemingway, los críticos y profesores de literatura "eran unos piojos que se arrastraban por las páginas de sus obras" (8). Veamos por qué.

En su célebre libro La guerra civil española, el historiador inglés Hugh

(7) Hugh Thomas, La guerra civil española (Barcelona: Grijalbo, 1983), p. 981.

(8) Meyers, p. 289. 
Thomas, explica que el relato intercalado que cuenta Pilar sobre las atrocidades hechas por republicanos y nacionales en su pueblo se basa en lo que realmente ocurrió en Ronda a principios del levantamiento militar del verano del 36 (9). Thomas también da la razón a Hemingway en cuanto a su descripción de la vida alegre y fácil en el cuartel general de la misión rusa en el hotel Gaylord en Madrid (10). Era, según Robert Jordan, "el lugar más confortable del Madrid sitiado» (11). Pero, al mismo tiempo, el hotel estaba lleno de mentiras, intrigas y corrupción. Así, desde un punto de vista histórico, la novela tiene sus aciertos. Con ellos, Hemingway quiere que el lector americano se haga una idea de lo que realmente ocurrió durante la guerra.

Hay un crítico americano, el profesor Carlos Baker, gran conocedor de Hemingway, que compara la estructura de Por quién doblan las campanas con la de una plaza de toros. Para él, la novela también está construida a base de círculos concéntricos. En el centro de la novela -en los medios- está el puente. Si los guerrilleros no logran destruirlo, se perderá la batalla, luego se perderá la guerra, y, poco después, el fascismo conquistará Europa y el mundo entero. No cabe duda que Hemingway apuntaba a eso en su novela, y que en los años treinta, muchos amigos de la República veían en la guerra civil el comienzo de otra contenda mundial (12).

Las mujeres de Por quién doblan las campanas han sido objeto de largos y calurosos debates entre los estudiosos. El novelista y crítico español, Arturo Barea, ataca duramente a Hemingway, alegando que una chica española de esa época nunca podría dormir con un hombre el mismo día que la conoció, tal y como lo hace la bella y sumisa María con Robert Jordan. Otro crítico, Jeffrey Meyers, autor de una reciente biografía de Hemingway, opina que Pilar, la matriarca de la banda, es un reflejo de la madre de Hemingway. Al parecer, la señora Hemingway hacía que su marido le sirviera el desayuno en la cama y que preparase también las otras comidas. El "¿Quién lleva los pantalones?" es otro tema universal en Hemingway.

Para dar más sabor español al libro, Hemingway concibió la idea de escribir mucho del texto con "española síntaxis», es decir, escribe como si estuviese traduciendo directa y literalmente todo lo que se dice,

(9) Thomas, p. 301.

(10) Thomas, p. 427.

(11) Ernest Hemingway, Por quién doblan las campanas (Barcelona: Bruguera, 1983), p. 209.

(12) Carlos Baker, Hemingway: The Writer as Artist (Princeton, New Jersey: Princeton University Press, 1963), pp. 245 y ss. 
ya que Robert Jordan sabe hablar español. Para transmitir el uso de la segunda persona del singular, el "tú" del castellano al inglés, Hemingway recurre a las formas "thee" $\mathrm{y}$ "thou" del inglés antiguo. El lector de hoy asocia "thee» $y$ "thou" con el lenguaje bíblico y estas formas arcaicas, efectivamente, refuerzan el tono religioso y solemne de la novela. También sugieren la antigüedad de la cultura española, además de mostrar la intimidad y solidaridad que existen entre los guerrilleros:(13). En este aspecto, la traducción española pierde mucho del encanto del original.

Asimismo, el cuerpo de la novela está salpicado con frases y palabras escritas en castellano. Y la verdad es que Hemingway comete errores de ortografía y de gramática. Todo esto produce más de una sonrisa en el lector bilingüe. Aquí los críticos no hacen más que cebarse en el escritor (14). Puede que tengan razón, pero incluso los escritores profesionales tienen sus problemas con la complicadísima gramática española. Pío Baroja tuvo que consultar con sus amigos para ver si un personaje suyo debía bajar una escalera "con zapatillas, en zapatillas o de zapatillas». Personalmente no sé cuántos años tardé en comprender que había una diferencia entre "dar la luz" y "dar a luz". Todos los que han viajado o estudiado en el extranjero han pasado por este tipo de experiencia.

\section{EL JARDÍN DEL EDÉN}

Hablemos brevemente de la última y, sin duda, la más atrevida y atípica de las novelas de Hemingway, El jardín del Edén, publicada en mayo de 1986. Hemingway empezó a escribirla en 1946, y fue elaborándola hasta su muerte. Escribió tres versiones, la más larga de unas 1.500 páginas. La forma publicada de la novela tiene 247 páginas. Sufrió, pues, grandes recortes.

El protagonista, David Bourne, es un joven escritor expatriado que acaba de publicar su segunda novela y vive pendiente de las reseñas que le manda su editor. La semejanza entre David y su creador se hace aún más obvia con la descripción de su rutina diaria. Trabaja intensamente

(13) Carlos Baker, Ernest Hemingway: Critiques of Four Major Novels (New York: Schribners, 1962), pp. 85-86.

(14) Véase el artículo de Allen Josephs "Hacia un estudio de la España de Hemingway", Insula, núm. 363, febrero 1977, pp. 1, 16. También el libro de John McCormick y Mario Sevilla Mascareñas, The Complete Aficionado (Cleveland: World Publishing, 1964), pp. 227-251. 
por la mañana, y por la tarde se divierte con su(s) mujer(es). Con este personaje Hemingway nos permite ver su proceso creativo y cómo "sudaba" sus obras.

La novela se ambienta en la Costa Azul y el Madrid de los años veinte. Tiene un aire evocativo y nostálgico. David pasa su luna de miel con su esposa Catherine. Esta, rica heredera, es caprichosa y veleidosa hasta el punto de haber perdido su identidad como mujer. Sus características psicofísicas van complicándose. Pasa el día al sol, y su bronceo y personalidad se oscurecen progresivamente. Su deseo de ser otro, y no otra, le empuja a cortarse y teñirse el pelo repetidas veces. Exige que su marido haga otro tanto. Este dominio/identificación con lo masculino dentro del joven matrimonio se desborda en la perversidad. En Madrid practican la sodomía. De nuevo en Francia, Catherine conoce a Marita, otra joven rica, guapa y sensual, y la invita a vivir con ellos. La relación homosexual entre las dos mujeres se convierte en un "menage a trois" y, finalmente, en un amor franco entre David y Marita. Catherine, "la víbora", es expulsada del jardín y se marcha, pero no sin antes quemar todos los manuscritos de su marido. Gracias al amor puro de Marita, David se recupera de la pérdida de su mujer y de su obra y descubre que ahora escribe mejor que antes.

En El jardín del Edén, Hemingway vuelve a su estilo telegráfico, podando y sugiriendo todo lo posible. Dada la tendencia escabrosa de la novela, esta técnica no debe extrañarnos. Hay que leer atentamente. Aun así hay pasajes casi incomprensibles. Acaso cortara demasiado el editor. Mucho del libro es dialogado, y las conversaciones frívolas resultan pesadas y sin interés. Ahora bien, una vez que el lector se deshace de su choque inicial, acaba dejándose encantar por el mundo idílico en que viven los personajes: hacen nudismo en las playas desiertas, se pasean en un Bugatti deportivo; y, abundan la buena comida, el caviar, el champán, la absenta... y el sexo. El resultado es una novela tremendamente sensual, impublicable en los Estados Unidos de los años cuarenta y cincuenta.

España desempeña un papel secundario en la novela. Sólo tres capítulos tienen lugar en Madrid. La pareja se escapa de Francia en busca de un nuevo jardín en la capital española. Se alojan en el Hotel Palace y pasan su tiempo comiendo, bebiendo y haciendo el amor. La neurosis sexual de Catherine se agrava y David, preso de sus remordimientos, ahoga su disgusto con absenta. Catherine también se disgusta porque España "es un país tan formal" (15). Al parecer, España vuelve a ser un

(15) Ernest Hemingway, The Garden of Eden (New York: Schribners, 1986), p. 55. (La traducción es mía) 
templete de la buena conducta, pero Catherine es capaz de convertir cualquier lugar en Sodoma y Gomorra. Asimismo, hay que recordar que España fue un "Jardín del Edén" para Hemingway, y que en esa época le estaba totalmente vedado.

\section{CONCLUSIONES}

Contestamos a nuestra pregunta inicial: ¿Cuánto sabía Hemingway de España? Se puede afirmar que trotó por España de arriba abajo, en todos los medios de transporte y bajo todas las circunstancias económicas. Vivió y comió en fondas y pensiones humildes y, ya famoso, disfrutó de palacios, hoteles y restaurantes de lujo. Trató con españoles de todos los rangos y niveles sociopolíticos: artistas, políticos, soldados, etc. Era un auténtico devorador de libros y conocía la obra de Lope, Calderón, Cervantes y Baroja. Conoció la dictadura de Primo de Rivera, la República y el franquismo. Si no hablaba bien castellano, al menos lo entendía. Esa habilidad (por menguada que fuese) le ayudó a comprender la personalidad española y a penetrar en los entresijos de una cultura tan antigua, complicada y variada como la española. Pensemos en los acontecimientos de los últimos diez años en España y lo difícil que es comprender todo lo que ha pasado. Hemingway sabía mucho de Espa$\tilde{n} a$, aunque no fuese tan experto como daba a entender.

¿Cuál era la España de Hemingway? En primer lugar, era un campo de juego, un sitio donde divertirse y relajarse. Eso siempre. Pero España se convirtió en un país de maravillas literarias, fascinante y hechicero, que había que comprender y explotar para sus fines novelísticos. Por eso, España también fue su laboratorio en el sentido exacto de la palabra. En ella Hemingway hizo observaciones e investigaciones. Recopiló datos y "sudón la redacción de varias de sus obras. Gracias a una enorme sensibilidad, Hemingway supo captar detalles que ampliaban el significado, "el mensaje» de su prosa. España le permite comparar y contrastar países, personajes y personalidades, llegando así a verdades más profundas. El paisaje español, tan variado, no sólo sirve como ambiente o trasfondo exótico, sino que tiene valores simbólicos y poéticos. Los personajes españoles de Hemingway representan, en muchos casos, valores humanos positivos: la valentía, la bondad y la generosidad. De estos personajes, el torero es el más fascinante. La "filosofía" vital de $\mathrm{He}-$ mingway - vivir a tope- se sintetiza en su idea del torero. Esa identidad penetra en muchos de sus personajes. La corrida es una tragedia repleta de ritos y símbolos. Ayuda a Hemingway a crear parte de la forma y el sentido de sus obras. Inevitablemente, los protagonistas americanos de Hemingway se enamoran de España y se españolizan. Heming- 
way compagina en ellos sus experiencias, ideas y esperanzas para con su segunda patria.

Para verdaderamente saber qué sentía Hemingway de España y los españoles, hay que comparar lo que dice de esta nación y su gente con lo que opina de otros países. Sabemos que para Hemingway su propio país era simplemente aburrido y mostró su desdén ignorándolo en su novelística. Hemingway se marchó de París en 1928. Creía que los franceses estaban obsesionados con el franco y de los militares franceses dijo: «Liberté, Venalité et Stupidité». Los italianos eran unos ladrones o, como mucho, buenos conductores de coches. De los cubanos más vale no decir nada. De los ingleses dijo que no los entendía, y que por teléfono, incluso peor (16). Pero, al hablar o escribir de España, el sarcasmo, la bravuconería y la aspereza desaparecían. El cielo, comentó una vez Hemingway, "sería una plaza de toros con dos entradas de barrera vitalicias y al lado de la plaza un río truchero exclusivamente para él" (17). En otra ocasión dijo que "todos los españoles eran unos buenazos" (18). El verano sangriento empieza así: “Era extraño volver a España otra vez. Nunca esperaba que se me permitiese volver al país que quería más que cualquier otro salvo el mío" (19). El elogio más alto que hizo de este país y de su gente fue que "nunca se sintió extranjero en España" (20). Y de este amor todo español puede sentirse muy orgulloso.

(16) Donaldson, pp. 279-81. La traducción es mía.

(17) Baker, A Life Story, p. 369. La traducción es mía.

(18) Baker, A Life Story, p. 169. La traducción es mía.

(19) Ernest Hemingway, The Dangerous Summer (New York: Schribners, 1985), p. 43. La traducción es mía.

(20) Baker, A Life Story, p. 415. La traducción es mía. 